\title{
Ethical Issues of Informed Consent: Students as Participants in Faculty Research
}

\author{
Phatcharapon Tulyakul ${ }^{1} \&$ Soontareeporn Meepring ${ }^{2}$ \\ ${ }^{1}$ Nurse Instructor, Borommarajonani College of Nursing, Trang, Thailand \\ ${ }^{2}$ Assistant professor, Department of Nursing, Faculty of Nursing, Naresuan University, Phitsanulok, Thailand \\ Correspondence: Soontareeporn Meepring, Department of Nursing, Faculty of Nursing, Naresuan University, \\ Phitsanulok, Thailand. Tel: 66-55-966-700 Ext.6721.E-mail: Soontareepornt@nu.ac.th
}

\author{
Received: November 20, 2019 Accepted: February 13, 2020 Online Published: February15, 2020 \\ doi:10.5539/gjhs.v12n3p86 \\ URL: https://doi.org/10.5539/gjhs.v12n3p86
}

\begin{abstract}
Educators may face an ethical dilemma when they conduct research by using their own students as participants. The dual role conflict, coercion, confidentiality, misconstruction, and unawareness of the informed consent documents have been discussed as ethical issues in such faculty research. The educators as the researchers should be aware of these ethical dilemmas and attempt to implement the informed consent effectively. Thus, this article explores the ethical considerations of informed consent for the educational setting that students are recruited in the faculty research. Furthermore, this article represented recommendations for potentially resolving the ethical dilemmas of informed consent surrounding this phenomenon which consisted of eliminating dual role conflict and coercion, guarding confidentiality, and promoting good construction and awareness of the informed consent documents
\end{abstract}

Keywords: ethical dilemma, dual role, informed consent

\section{Introduction}

Regarding ethical standards for researches involving human subjects, informed consent is an inevitable procedure of research methodology (Association of Clinical Research professionals, 2013). The objective of informed consent is to provide important information and authorization for members of the research population before they consent to engage the research projects as participants (Faden \& Beauchamp, 2008). It is necessary that informed consent should include transparent and adequate information, such as descriptive information about research processes, rights of subjects, potential risks and benefits of participants, and confidentiality (Association of Clinical Research Professionals, 2013; Ganguly, 2016; Nambiar, Christopher, Mammen, David, Kang, \& David, 2012; Shahnazarian, Hagemann, Aburto, \& Rose, n.d.; Melnyk \& Fineout-Overholt, 2011).

Informed consent interweaves ethical and legal concerns in terms of autonomous authorization and effective consent in human subjects (Faden \& Beauchamp, 2008). Although many informed consent guidelines such as the Nuremberg Code, the Declaration of Helsinki, and the Belmont Report set the rules and regulations to protect participants from harms during the research intervention, various harms remain during the informed consent process (Escobedo, Guerrero, Lujan, Ramirez, \& Serrano, 2007; Faden \& Beauchamp, 2008). Ineffective communication, false expectations of the experiment outcome, power of researcher toward the voluntariness of participants, and lack of transparency in informed consent process are being addressed as harms associated with ethical issues of the informed consent process (British Educational Research Association, 2011; Escobedo et al., 2007; Ganguly, 2016; Nijhawan et al., 2013). However, the ethical issues might vary, based on the application of informed consent in different research circumstances.

In the educational setting, faculty members were required to conduct research in accordance with the job description of tenure-earning faculty (Shao, Anderson, \& Newsome, 2007). Typically, the population of faculty's research projects in educational circumstances is students in their own classes. It is undeniable that ethical issues take place when teacher researchers select their own students as research participants. Since the relationship between teacher researchers and student participants might affect the voluntariness in the decision-making process of students, ethical dilemmas during this process such as inducement, force, fraud, and other forms of coercion will arise. Likewise, conflict of the dual role of the teachers as the researchers, and the power of teacher researchers 
toward students, can be a cause of the coercion during the informed consent process (Ferguson, Yonge, \& Myrick, 2004).

For faculty's research projects in educational circumstances, ethical issues arise when teacher researchers select their own students as research participants. It is a challenge for teacher researchers to avoid and diminish harms that might happen to student participants. Although teacher researchers know that obtaining informed consent is a crucial requirement in order to protect participants, some teacher researchers do not entirely understand and show concern for all dimensions of participants' rights in the informed consent process (Nambiar et al., 2012). This paper explores the ethical considerations of informed consent in the educational setting that students are involved in faculty research. Recommendations for potential resolving of the ethical dilemmas of informed consent surrounding this phenomenon are indicated.

\section{The Foundation of Informed Consent}

The fundamentals of informed consent are issued in the Nuremberg Code, the Declaration of Helsinki, and the Belmont Report as guidelines for the protection of human subjects of research (Carlson, Boyd, \& Webb, 2004; Shister, 1997; The National Commission for the Protection of Human Subjects of Biomedical and Behavioral Research, 1979). In biomedical and behavioral research, informed consent is used to protect human subjects from force, fraud, and any kinds of coercion. These three principles of informed consent regulate researchers regarding the elements, contents, and ethical considerations of the informed consent documents. The consent documents must be applied to the research subjects before they make a decision to be research participants (Carlson et al., 2004; Shister, 1997). The content of informed consent documents should include the purposes of research, procedures and alternatives, conflicts of interest, potential risks, compensation, anticipated benefits, statement of confidentiality, and researcher's information (Carlson et al., 2004; Nambiar, 2012; Nijhawan et al., 2013; Shister, 1997). The National Commission for the Protection of Human Subjects of Biomedical and Behavioral Research (1979) recommended that the informed consent forms include a statement giving participants an opportunity to ask questions and to withdraw from the research whenever they want. Additionally, the researchers have to respect the privacy and confidentiality of research subjects (Carlson et al., 2004; Shister, 1997). The information in the consent forms must fit properly with the subjects' capacities so that subjects are able to understand. After researchers ensure that the subjects have understood the information in the consent documents, the researchers should allow the subjects to document their consent with voluntariness and without coercion(Carlson et al., 2004; The National Commission for the Protection of Human Subjects of Biomedical and Behavioral Research, 1979).

\section{The Ethical Considerations of Informed Consent Process in the Educational Setting}

\subsection{Dual Role Conflict: Teacher and Researcher}

Dual role conflict has been noted as an ethical dilemma when teachers conduct research studies with their own students (Hammack, 1997). The ambiguity and overlap of the dual role have an effect on students' decision in the informed consent process (Hammack, 1997). The dual role conflict has arisen when teachers conducted the experimental research and action research (Loftin, Campanella, \& Gilbert, 2011; Shi, 2006). Shi (2006) expressed his ethical dilemma experience of dual role conflict in the following terms: I sensed an uneasy feeling about the idea of research among students immediately following my explanation of the research and how it was separated from the coursework. There was tension among students about being used as research subjects. Several students expressed their doubts whether the research was intended for other purposes and whether it was fair to include research in the course. For example, some asked whether the questionnaire and discussion data might be used by one of my graduate students for a thesis study. Others wondered whether I was using their labor to create the website for my own professional promotion. I felt guilty about having placed the students in the awkward situation. (p. 214-215).

According to Shi (2006), the dual role conflict happens when teachers try to play teacher and researcher role simultaneously. As a researcher, teachers expect that the experimental group should display the better result than the control group. By contrast, teachers at heart must provide equal instructions and benefits for all students in their classes. Cleary, Walter, and Jackson (2014) declared that this phenomenon could be considered as the conflict of interest that was one of the potential problems in relation to dual role conflict.

\subsection{Coercion}

Intrinsically coercion occurs when teachers ask their own students to participate in their research because a relationship between teachers and students can affect students' choices to volunteer (Bradbury-Jones, Stewart, Irvine, \& Sambrook, 2011; Ferguson, Myrick, \& Youge, 2006; Hammack, 1997). Students who are asked to participate in their faculty's research might feel reluctant when they notice the undesirable experimental 
intervention or intense workload (The Open University, 2005). Besides, offering the incentives is another form of coercions when teachers propose an extra credit or bonus point as a reward for student participation in faculty's research projects (Cleary et al., 2014; Loftin et al, 2011). Clearly et al. (2014) declared, in addition, that offering the financial incentive to students engaging in educator research studies could be define as coercion. In contrast, teacher-researchers might feel dissatisfied and give the negative responses to students who refuse to involve or withdraw from their research projects (Hammack, 1997).

\subsection{Confidentiality}

The infringement of student-participants' confidentiality is one of the ethical issues concerning teachers' research studies, particularly with respect to data collection and research methodology (Loftin et al., 2011). Student-participants might face difficulty in the situation that they are reluctant to reveal personal or confidential information because they might desire to keep their answer in private (Loftin et al., 2011). Cleary et al. (2014) described that the potential ethical issue regarding the confidentiality may happen in the qualitative studies because it is difficult to conceal the participants' identity. Likewise, student-participants might not want to be alienating with their teacher-researchers after they provide the private information or negative information relating to teacher-researchers (Loftin et al., 2011).

\subsection{Misconstruction and Unawareness of the Informed Consent Documents}

Many ethical issues are interwoven with the informed consent process when the teacher-researchers have a lack of knowledge in construction and implementation of the informed consent forms, such as lack of knowledge concerning the information that should be included in the informed consent. Besides, the unawareness of student-participants in reading and understanding the informed consent documents might be a cause of the ethical issue. Pedersen, Neighbors, Tidwell, and Lostutter (2011, p. 333) stated, "Documentation of informed consent may not actually indicate informed consent if a participant did not thoroughly read the consent document or if they did not fully understand what they read". Pederson et al. (2011) revealed that most of the undergraduate participants in psychological survey study avoided reading the information in the consent forms carefully. In so doing, student participants might not recognize the important information in the informed consent forms, such as the risks, benefits, confidentiality procedures, and so forth prior to participation. In particular, when students are asked to be involved in the teacher-researchers' studies, they might not pay attention to reading the informed consent forms because they trust in their teachers.

\section{Recommendations for Potentially Resolving the Ethical Issues of Obtaining Informed Consent}

\subsection{Eliminating Dual Role Conflict and Coercion}

Some strategies to dissolve dual role conflict and coercion in this circumstance are recommended. First, teacher-researchers should avoid recruiting their own students as research participants (Grant \& Sugarman, 2004; Hammack, 1997). However, if the teachers cannot avoid using students in their classes, they should allow third persons to explain the information of informed consent and collect consent forms, as well as keep the informed consent forms until the final grades for this class have been submitted (Cleary et al., 2014; Ferguson et al., 2006; Ridley, 2009). Second, teacher-researchers should provide students adequate time to make a decision-at least 24 hours (Cleary et al., 2014). Third, teacher-researchers should ensure that students' decision to participate in teachers' research must be made in the voluntariness atmosphere and without any coercion (Cleary et al., 2014; Hammack, 1997; Ridley, 2009).

\subsection{Guarding Confidentiality}

Regarding ethical issues about confidentially, teacher-researchers must include clear and understandable statements in the informed consent documents in terms of grading confidentiality. Ethics Review Office, University of Toronto (2003) suggested that teacher-researchers must ask students' consent if any materials produced by the students are to be collected and analyzed in the research projects. Fully informed consent on how the students' materials will be used, with guarantees of confidentiality are essential (Ethics Review Office, University of Toronto, 2003). Moreover, Cleary et al. (2014) suggested that the information in the informed consent should include the statement of confidentiality to ensure that student-participants information will be coded wherever possible to maintain anonymity. Besides, the information of students who refuse to participate in the research projects must be kept in secret from faculty researchers (Ferguson et al, 2006).

\subsection{Promoting Good Construction and Awareness of the Informed Consent Documents}

In the decision-making process concerning participation in the research projects, teacher-researchers must provide the informed consent document including clear and concise information to students (Ridley, 2009). The 
information in the informed consent forms should explicitly state that no penalties would result from refusing to participate (Cleary et al., 2014; Ethics Review Office, University of Toronto, 2003). In addition, the informed consent form should make clear information about the voluntary participation clause, the possible risks, benefits, confidentiality procedures, randomization method, expected study duration, researchers' contact information, and alternative options (Clemson University IRB, 2005; Ferguson et al., 2006; Ridley, 2009). Ferguson et al. (2006) also suggested that the important information in the informed consent forms, such as the risks, benefits, voluntary participation, withdrawal statement, and rights as research participants must be communicated with participants prior to students signing the informed consent forms.

\section{Conclusion}

Since the didactic research studies are necessary for the development of the educational effectiveness, many teachers attempt to conduct research for testing their assumptions or interventions in teaching and learning. In so doing, students are the main population involving teachers' research projects. Teacher-researchers might perceive the ease of using students in their classes as research participants. Even though the teacher-researchers use the informed consent documents to protect the student participants' rights, the ethical issues still arise because of the nature of research and teacher-student relationships such as the dual role conflict, coercion, and confidentiality. Additionally, lack of knowledge in construction and unawareness of the informed consent documents can be the cause of ethical issues. Therefore, eliminating dual role conflict and coercion, guarding confidentiality, and promoting good construction and awareness of the informed consent documents are recommended steps for resolving the ethical issues of establishing informed consent for the teacher-researcher studies.

\section{Competing Interests Statement}

The authors declare that there are no competing or potential conflicts of interest.

\section{References}

Association of Clinical Research Professionals. (2013). The process of informed consent. Retrieved from https://www.acrpnet.org/wp-content/uploads/2016/09/ACRPWhitePaperTheProcessof InformedConsent.pdf

Bradbury-Jones, C., Stewart, S., Irvine, F., \& Sambrook, S. (2011). Nursing students' experiences of being a research participant: Findings from a longitudinal study. Nurse Education Today, 31, 107-111.

British Educational Research Association. (2011). Ethical guidelines for educational research. Retrieved from https://www.bera.ac.uk/wp-content/uploads/2014/02/BERA-Ethical-Guidelines-2011.pdf

Carlson, R. V., Boyd, K. M., \& Webb, D. J. (2004). The revision of the Declaration of Helsinki: Past, present and $\begin{array}{llll}\text { future. British Journal of clinical Pharmacology, 57(6), 695-713 } & \end{array}$ https://doi.org/10.1111/j.1365-2125.2004.02103.x

Cleary, M. Walter, G., \& Jackson, D. (2014). Above all, 'do no harm': Key considerations when including students as research participants in higher education setting. Contemporary Nurses, 49, 93-95.

Clemson University IRB. (2005). Guidance on the use of students as research participants. Retrieved from $\mathrm{http}: / /$ media.clemson.edu/research/compliance/irb/students-research-participants.pdf

Escobedo, C. Guerrero, J., Lujan, G., Ramirez, A., \& Serrano, D. (2007). Ethical issues with informed consent. Bio-Ethics, 1(Fall), 1-8.

Ethics Review Office, University of Toronto. (2003). Teacher-researcher conflicts of interest. Retrieved from http://www.research.utoronto.ca/wp-content/uploads/documents/2013/05/teacher-researcher-role-based-conf lict-c2003.pdf

Faden, R. R. \& Beauchamp, T. L. (2008). The concepts of informed consent. In T. L. Beauchamp, L. Walters, J. P. Kahn, \& A. C. Mastroianni (Eds.). Contemporary Issues in Bioethics ( $7^{\text {th }}$ ed.). (pp. 170-175). Belmont: Wadsworth Cengage Learning. (Reprinted from A History and Theory of Informed Consent, pp.276-286, by R. R. Faden \& T. L. Beauchamp, 1986, New York, NY: Oxford University Press.

Ferguson, L. M. Yonge, O., \& Myrick, F. (2004). Students' involvement in faculty research: ethical and methodological issues. https://doi.org/10.1177/160940690400300405

Ferguson, L. M. Myrick, F., \& Yonge, O. (2006). Ethically involving students in faculty research. Nurse Education Today, 26(8), 705-711. https://doi.org/10.1016/j.nedt.2006.07.021

Ganguly, B. (2016). Newer practice of informed consent process of clinical trials in India. Asian Bioethics Review, 8(4), 327-336. https://doi.org/10.1353/asb.2016.0027 
Grant, R. W., \& Sugarman, J. (2004). Ethics in human subjects research: Do incentives matter? Journal of Medicine and Philosophy, 29(6), 717-738. https://doi.org/10.1080/03605310490883046

Hammack, F. M. (1997). Ethical issues in teacher research. Teachers College Record, 99(2), 247-265.

Loftin, C., Campanella, H., \& Gilbert, S. (2011). Ethical issues in nursing education: The dual-role research. Teaching and Learning in Nursing, 6, 139-143. https://doi.org/10.1016/j.teln.2011.01.005

Melnyk, B., \& Fineout-Overholt, E. (2011). Evidence-based practice in nursing \& healthcare: A guide to best practice $\left(2^{\text {nd }}\right.$ ed.). Philadelphia: Lippincott.

Nambiar, A., Christopher, D. J., Mammen, J., David, T., Kang, G., \& David, S. (2012). Informed consent among nursing students participants in biomedical research. Indian Journal of Medical Ethics, IX(3), 186-189.

Nijhawan, L. P., et al. (2013). Informed consent: Issues and challenges. Journal of Advanced Pharmaceutical Technology \& Research, 4(3), 134-140. http://doi.org/10.4103/2231-4040.116779

Pederson, E. R., Neighbors, C. Tidwell, J., \& Lostutter, T. W. (2011). Do undergraduate student-research participants read psychological research consent forms? Examining memory effects condition effects, and individual differences. Ethics \& Behavior, 21(4), 332-350. https://doi.org/10.1080/10508422.2011.585601

Ridley, R. T. (2009). Assuring ethical treatment of students as research participants. Journal of Nursing Education, $48(10), 537-541$.

Shahnazarian, D. Hhagemann, J., Aburto, M., \& Rose, S. (n.d.). Informed consent in human subjects research. Retrieved from http://oprs.usc.edu/files/2013/04/Informed-Consent-Booklet-4.4.13.pdf

Shao, L. P., Anderson, L. P., \& Newsome, M. (2007). Evaluating teaching effectiveness: Where we are and where we should be. Assessment \& Evaluation in Higher Education, 32(3), 355-371.

Shi, L. (2006). Students as research participants or as learners? Journal of Academic Ethics, 4, 205-220. doi:10.1007/s10805-006-9028-y https://doi.org/10.1007/s10805-006-9028-y

Shister, E. (1997). Fifty years later: The significance of the Nuremberg code. The New England Journal of Medicine, 13, 1436-1440.

The National Commission for the Protection of Human Subjects of Biomedical and Behavioral Research. (1979). The Belmont report: Ethical principles and guidelines for the protection of human subjects of research. Retrieved from https://archive.org/details/belmontreporteth00unit

The Open University. (2005). Action Research A Guide for Associate Lecturers. Retrieved from http://www.open.ac.uk/cobe/docs/AR-Guide-final.pdf

\section{Copyrights}

Copyright for this article is retained by the author(s), with first publication rights granted to the journal.

This is an open-access article distributed under the terms and conditions of the Creative Commons Attribution license (http://creativecommons.org/licenses/by/4.0/). 